\title{
PENINGKATAN PROFESIONALISME GURU SDN 2 PALEMBANG MELALUI PENGEMBANGAN MEDIA PEMBELAJARAN BERBASIS MULTIMEDIA
}

\author{
Irma Salamah ${ }^{1}$, Raden Kusumanto ${ }^{1}$, Lindawati ${ }^{1}$ \\ ${ }^{1}$ Politeknik Negeri Sriwijaya, Palembang, Indonesia \\ irma.salamah@yahoo.com
}

\begin{abstract}
Abstrak: Perkembangan teknologi informasi menjadi salah satu peluang yang dapat dimanfaatkan guru dalam meningkatkan kualitas pembelajaran di kelas. Banyaknya perangkat lunak (software) yang tersedia dapat dimanfaatkan guru untuk mengembangkan media pembelajaran yang lebih interaktif dan menarik minat belajar siswa. Program pengabdian kepada masyarakat (PKM) ini bertujuan untuk meningkatkan profesionalisme guru-guru Sekolah Dasar Negeri (SDN) 2 Palembang dalam membuat media pembelajaran berbasis komputer dan multimedia sehingga lebih meningkatkan efisiensi waktu penyampaian materi pembelajaran dan proses belajar mengajar menjadi lebih menarik. Metode yang digunakan dalam kegiatan ini adalah metode ceramah, praktek/pelatihan, dan tanya jawab. Hasil PKM ini menunjukkan guruguru SDN 2 Palembang dapat mengikuti pelatihan ini dengan baik. Melalui kegiatan ini guru dapat membuat presentasi berbasis media dan mampu menambahkan animasi pada media tersebut sehingga menjadi lebih menarik. Dengan demikian kegiatan pelatihan pengembangan media pembelajaran berbasis multimedia ini efektif dalam meningkatkan profesionalisme guru sekolah dasar.
\end{abstract}

Kata Kunci: media pembelajaran, multimedia, profesionalisme guru

\begin{abstract}
The development of information technology is one of the opportunities that can be utilized by teachers to improve the quality of learning in the classroom. A large amount of available software can be used by teachers to develop interactive learning media and attract students' interest in learning. This community service program aims to improve the teachers' professionalism in Palembang Elementary School (SDN) 2 in making computer-based and multimedia-based learning media so as to increase the efficiency of time delivery of learning materials and teaching and learning processes become more interesting. The method used in this program was the lecture, practice/training, and question and answer. The results showed that the teachers of SDN 2 Palembang take part in this training well. Through this activity, the teachers are able to make a media-based presentation and add animation to the media so that it becomes more interesting. Thus, the training of developing multimedia-based learning media is effective in increasing the professionalism of elementary school teachers.
\end{abstract}

Keywords: instructional media, multimedia, teacher professionalism

\section{Pendahuluan}

Kemajuan teknologi mempunyai peranan penting dalam dunia pendidikan. Pendidikan adalah pembelajaran pengetahuan dan keterampilan melalui pengajaran, bimbingan, atau pelatihan. Dengan adanya kemajuan teknologi tentunya pendidik dan peserta didik harus bisa beradaptasi dengan penggunaan teknologi tersebut. Namun pada kenyataannya masih ada pendidik yang kurang mampu dalam memahami penggunaan teknologi tersebut (Hartono, Lesmana, Permana, Matsun, 2018)

Penerapaan teknologi pembelajaran kini sedang menjadi perbincangan hangat di kalangan para praktisi pendidikan. Sekolah berlomba-lomba untuk menciptakan program pembelajaran yang berbasis teknologi. Seakan-akan mereka menganggap bahwa dengan 
menerapkan teknologi di dalam proses pembelajaran akan menjamin pembelajaran itu berhasil. Hal tersebut diikuti dengan perkembangan teknologi di Indonesia yang semakin pesat. Akan tetapi perkembangan itu juga diiringi dengan pro dan kontra dari masyarakat (Nina, 2016).

Sebelum internet berkembang, proses pembelajaran di sekolah masih berlangsung secara konvensional. Guru berceramah atau menyampaikan informasi atau materi langsung secara lisan kepada siswa. Cara pembelajaran seperti ini tidak membutuhkan banyak alat bantu. Sumber pembelajaran sangat tergantung dari buku-buku literature yang ada. Jika ada pertanyaan murid-murid bertanya guru akan langsung menjawab (Nugraheni, 2013). Papan tulis dan buku cetak merupakan media pembelajaran yang diandalkan dalam sistem pembelajaran konvensional ini. Guru berdiri di depan kelas memberikan penjelasan materi dengan ilustrasi yang sederhana. Guru menuliskan materi di papan tulis, menerangkan materi tersebut kemudian siswa mencatat apa yang ditulis dan diterangkan oleh guru. Buku cetak merupakan hal yang wajib dimiliki oleh guru dan siswa karena buku cetak merupakan sumber pembelajaran yang utama. Selain itu apabila ada tugas yang diberikan siswa harus mengumpulkan tugas secara langsung kepada guru.

Guru juga menentukan buku cetak apa yang harus dimiliki oleh murid sebagai pegangan untuk belajar di rumah, membuat PR, dan latihan soal. (Supriyono, Sujalwo, Sapoetra, \& Rahayu, 2015). Semenjak masuknya teknologi dalam dunia pendidikan, banyak perubahan yang terjadi dalam proses pembelajaran. Berikut perubahan-perubahan tersebut (Nina, 2016) antara lain: (1) papan tulis digantikan proyektor, (2) buku teks digantikan e-book, (3) dahulu tugas dikumpulkan langsung kepada guru, sekarang tugas dikirim melalui email, dan (4) dahulu mencari bahan belajar ke perpustakaan, sekarang mencari bahan belajar dengan membuka internet.

Guru yang professional harus dapat menciptakan kondisi belajar yang menantang kreativitas, aktifitas, memotivasi siswa, dan menggunakan multimedia. Dalam undang-undang guru dan dosen menyatakan bahwa seorang guru harus mempunyai kompetensi pedagogik, kepribadian sosial, dan professional (Rusman, 2011). Era profesionalisme para guru tidak hanya dituntut untuk memenuhi beban tugas mengajar 24 jam seminggu, tetapi juga dituntut untuk lebih produktif dan meningkatkan efektivitas pola pembelajaran yang dilaksanakannya (Riskiawan, Setyohadi, \& Arifianto, 2016).

Peranan teknologi informasi di sekolah fungsinya sangatlah penting dimana dapat mengubah metode komunikasi dalam pemberian materi yang bervariasi kepada siswa. Untuk mengimbanginya para tenaga pendidik haruslah melek teknologi, membuat tenaga pendidik bias memanfaatkan teknologi informasi pada media pembelajaran di dalam kelas. Dengan mengaplikasikan materi pembelajaran misalnya dalam bentuk PowerPoint. Dimana lewat PowerPoint, tenaga pendidik bisa menampilkan gambar, video, audio serta membuat desain materi pelajaran lebih menarik. Sehingga, peserta didik antusias mengikuti pelajaran bukan monoton dan membosankan. Di samping itu, penggunaan teknologi informasi membuat interaksi guru dengan murid dalam proses belajar mengajar di dalam kelas menjadi hidup dan dua arah. Di lain sisi guru harus lebih aktif untuk mendalami materi-materi pembelajaran yang 
belum bisa didapatkan dari cara belajar konvensional. Di sisi lain proses pembelajaran memanfaatkan multimedia lebih berperan sebagai fasilitator, dengan keunggulannya tersebut membuat program pembelajaran berbasis teknologi informasi mempunyai kemampuan untuk mengisi kekurangan tenaga pendidik, namun tentu saja bukan menjadi jaminan media mampu menggantikan peran guru, karena masih banyak hal-hal yang bersifat humanisme yang tidak bias digantikan oleh komputer (Analisadaily, 2017).

Teknologi multimedia telah menjanjikan potensi besar dalam merubah cara seseorang untuk belajar, untuk memperoleh informasi, menyesuaikan informasi dan sebagainya (Yossie, 2011). Multimedia interaktif adalah suatu multimedia yang dilengkapi dengan alat pengontrol yang dapat dioperasikan oleh pengguna, sehingga pengguna dapat memilih apa yang dikehendaki untuk proses selanjutnya. Contoh multimedia interaktif adalah: multimedia pembelajaran interaktif, aplikasi game, dll. Sedangkan pembelajaran diartikan sebagai proses penciptaan lingkungan yang memungkinkan terjadinya proses belajar.

Menurut Rosch Multimedia dapat diartikan sebagai kombinasi dari komputer dan video. Kombinasi dari paling sedikit dua media input atau output. Media ini dapat berupa audio (suara, musik), animasi, video, teks, grafik dan gambar (Gilbert, 2002). Hofstetter mengatakan, multimedia adalah pemanfaatan komputer untuk membuat dan menggabungkan teks, grafik, audio, gambar bergerak (video dan animasi) dengan menggabungkan link dan tool yang memungkinkan pemakai melakukan navigasi, berinteraksi, berkreasi dan berkomunikasi, menggabungkan link dan tool yang memungkinkan pemakai melakukan navigasi, berinteraksi, berkreasi dan berkomunikasi (Mayer \& Moreno, 1998).

Pendidikan dan pengajaran sangat dipengaruhi oleh pesatnya perkembangan teknologi informasi. Berbagai media pembelajaran telah tercipta dengan adanya perkembangan tenologi informasi tersebut. Salah satu media pembelajaran yang berkembang dengan adanya perkembangan teknologi informasi ini adalah media pembelajaran multimedia. Multi media merupakan gabungan satu media pembelajaran dengan media pembelajaran yang lain. Secara umum multimedia adalah menggunakan beberapa media untuk menghadirkan informasi yang merupakan kombinasi antara teks, grafik, animasi, gambar, video dan suara (Ivers \& Barron, 2002). Materi yang diberikan dengan menggunakan multimedia akan menjadi lebih menarik. Materi dapat di tampilkan dengan memberikan animasi pada tulisan dan gambar. Selain itu pemberian warna dan suara akan membuat siswa lebih mudah memahami materi dengan pembelajaran yang diberikan guru (Afrida, Harizon, Bakar, \& Sanova, 2018).s

Sekolah Dasar Negeri 02 Palembang merupakan sekolah dasar negeri yang memiliki jumlah guru sebanyak 33 orang dengan guru tetap PNS sebanyak 24 orang, serta Guru Tidak Tetap (GTT) sebanyak 9 orang. Dari total seluruh guru sebanyak 20 orang guru ( sebesar $61 \%$ ) berusia diatas 50 tahun. Walaupun ada beberapa guru yang berusia muda, namun pemanfaatan teknologi informasi di SDN 02 Palembang untuk mendukung kegiatan belajar mengajar masih belum maksimal. Hal ini tergambar dari hasil observasi tim pengabdian masyarakat di SDN 02 Palembang menunjukkan bahwa fasilitas perangkat komputer yang dimiliki oleh guru-guru belum dapat dimanfaatkan secara maksimal untuk menunjang pekerjaan guru-guru terutama dalam sisi akademis. Sekolah Dasar Negeri 02 Palembang saat ini walaupun belum memiliki 
website sekolah, namun sudah memiliki fasilitas internet dengan wifi. Secara umum, proses belajar mengajar di Sekolah Dasar Negeri 02 Palembang juga masih berbasis pada material cetak saja.

Rendahnya produktivitas guru SDN 02 Palembang dalam menyiapkan materi pembelajaran berbasis komputer disebabkan karena kurangnya pengetahuan mengenai cara mencari informasi yang berkaitan dengan materi yang diajarkan dengan memanfaatkan teknologi informasi, serta belum familiar menggunakan tools aplikasi komputer yang ada. Sebagian besar guru SDN 02 Palembang kurang paham akan pemanfaatan aplikasi tersebut, sehingga berimbas pada kreativitas dan produktivitas dalam menyiapkan materi pembelajaran yang menarik dan berkualitas. Oleh karena itu, kegiatan ini bertujuan untuk meningkatkan profesionalisme guru-guru SDN 02 Palembang dalam membuat media pembelajaran berbasis komputer dan multimedia sehingga lebih meningkatkan efisiensi waktu penyampaian materi pembelajaran dan proses belajar mengajar menjadi lebih menarik. Dengan demikian minat belajar siswa dapat lebih meningkat.

\section{Metode}

Kegiatan pelatihan dilaksanakan selama 1 hari yaitu pada tanggal 18 Maret 2020. Pelatihan dimulai pukul 8.00 sampai pukul 15.30 WIB. Pelatihan dilaksanakan di ruang kelas SDN 02 Palembang. Guru-guru yang mengikuti pelatihan sebanyak 20 orang guru dari berbagai mata pelajaran. Tim pengabdi yang memberikan pelatihan ini sebanyak 3 orang dosen. Modul materi yang telah disiapkan oleh tim pengabdi dibagikan kepada guru-guru SDN 02 Palembang. Dengan adanya modul tersebut dapat membantu guru-guru SDN 02 palembang untuk lebih memahami pembuatan slide dengan menggunakan PowerPoint. Pembagian tugas tim pengabdi adalah 1 orang tim pengabdi menyajikan materi melalui slide dan 2 orang tim pengabdi yang lain melakukan pendampingan praktek langsung pada para peserta.

Sebelum pelatihan dimulai para guru diberikan angket yang berisi daftar pertanyaan untuk mengetahui bagaimana keadaan guru-guru SDN 02 Palembang terhadap penggunaan PowerPoint sebagai media pembelajaran di kelas. Angket pelatihan PowerPoint dapat dilihat pada tabel 1 (terlampir).

Kegiatan pengabdian menggunakan tiga metode yang dapat diuraikan sebagai berikut:

\section{Metode Ceramah}

Metode ceramah adalah memberikan penjelasan (ceramah) di kelas mengenai teori dasardasar multimedia, dasar-dasar Microsoft PowerPoint 2010, dan dasar-dasar pembuatan media pembelajaran interaktif menggunakan PowerPoint 2010 (Menu, Materi, kuis dan konversi ke video)

2. Metode Praktek/Pelatihan

Metode ini dilakukan dengan pelatihan dan praktek langsung. Peserta menerapkan secara langsung cara membuat presentasi menggunakan perangkat lunak Microsoft PowerPoint 2010 sehingga lebih mudah dipahami. Sehingga apa yang menjadi tujuan dalam pelatihan ini dapat tercapai. Kegiatan ini dilakukan pada tanggal 18 Maret 2020 di SDN 02 Palembang. 
Susunan acara dan jadwal kegiatan meliputi tahap pengenalan multimedia, multimedia pembelajaran, pembuatan aplikasi multimedia interaktif mulai dari instalasi software utama dan pendukung sampai ke tahap pertahap pembuatan aplikasi, dilanjutkan dengan tanya jawab.

3. Metode Tanya Jawab

Metode ini dilakukan dengan berdiskusi atau tanya jawab selama praktek/pelatihan berlangsung. Para peserta dapat langsung bertanya apabila ada yang tidak dimengerti berkaitan dengan materi yang telah dijelaskan.

Adapun bagan kegiatan pengabdian dapat dilihat pada gambar 1 dibawah ini.

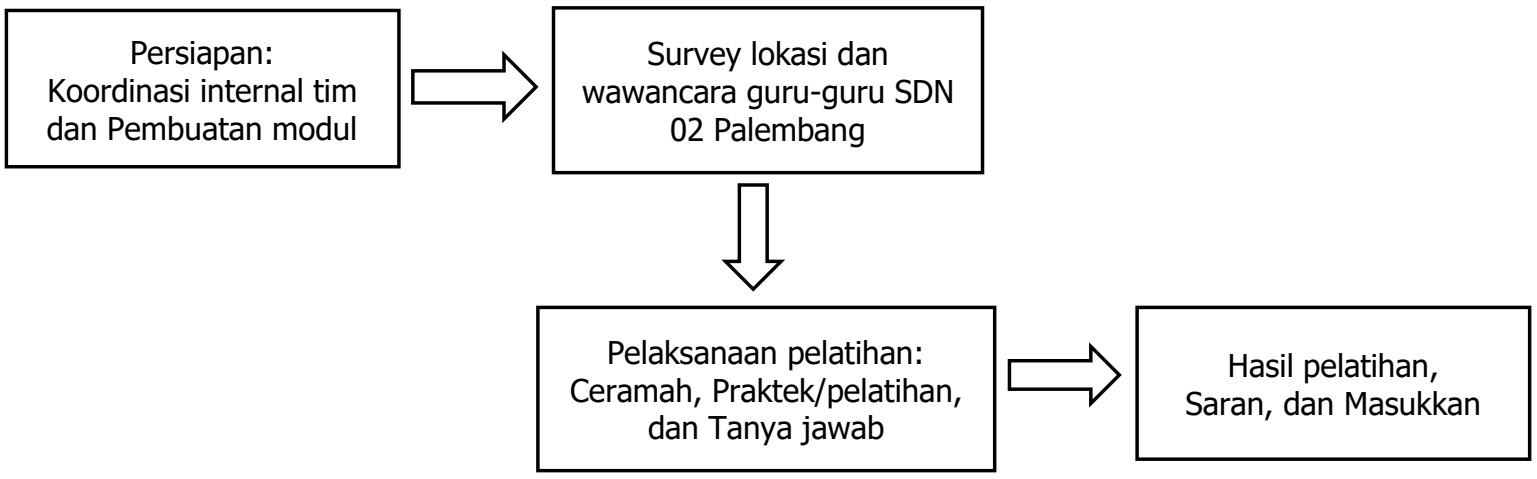

Gambar 1. Bagan kegiatan pengabdian

\section{Hasil dan Pembahasan}

Sebelum pelatihan dilaksanakan, terlebih dahulu tim pengabdi melakukan survey (tanya jawab) kepada guru-guru SDN 02 Palembang untuk mendapatkan data apa yang paling dibutuhkan guru dalam penguasaan ketrampilan komputer untuk meningkatkan profesionalisme dalam pengajaran di kelas. Dari hasil survey tersebut diketahui bahwa kebanyakan guru ingin meningkatkan profesionalisme mereka dengan menggunakan PowerPoint saat mengajar di kelas. Dari hasil survey juga ada beberapa guru yang sudah cukup mahir menggunakan PowerPoint sebagai alat presentasi di kelas, tetapi belum menggunakan PowerPoint untuk memberikan kuis kepada siswanya. Untuk kelancaran pelatihan, pihak sekolah meminta masingmasing peserta membawa notebook/laptop.

Hasil dari angket yang diberikan kepada 33 orang guru SDN 02 Palembang, sebanyak 18 orang guru menyatakan bahwa mereka mengetahui apa itu PowerPoint, tetapi mereka tidak menggunakannya sebagai media pembelajaran di kelas. 15 orang guru pernah menggunakan PowerPoint dalam pembelajaran di kelas. Secara keseluruhan ke 33 guru-guru SDN 02 Palembang mengetahui fitur-fitur yang ada pada PowerPoint, tetapi hanya 13 orang yang mengerti dan memahami fitur-fitur tersebut. Demikian juga dengan cara membuat materi dan memberikan animasi, hanya 13 orang yang memahaminya. Sedangkan untuk konversi ke video dan membuat kuis semua guru-guru SDN 02 Palembang tidak memahaminya.

Bentuk pelatihan meliputi pemberian materi kajian dasar dan materi kajian yang dijabarkan dalam langkah-langkah kerja. Pembahasan materi tersebut sesuai dengan materi 
yang telah dipersiapkan. Pembahasan menyangkut pengertian sampai ke manfaat aplikasi multimedia pembelajaran. Pembahasan juga dilanjutkan dengan praktek/pelatihan penggunaan dasar-dasar PowerPoint. Pada saat praktek langsung membuat slide guru-guru didampingi secara langsung agar materi lebih cepat dikuasai. Selain itu tanya jawab juga sangat membantu penguasaan para guru dalam memahami pembuatan slide dengan menggunakan PowerPoint.

Dari hasil observasi tim pengabdi di lapangan, peserta cukup antusias dengan adanya pelatihan ini. Hal ini ditandai dengan rata-rata peserta membawa notebook/laptop masingmasing untuk mencobakan setiap arahan yang diberikan instruktur dalam pelatihan. Antusiame para guru juga terlihat dari aktifnya diskusi antara guru-guru dan tim pengabdi dimana guruguru akan langsung menanyakan apabila ada hal belum mereka mengerti. Kendala yang ada dalam pelatihan ini adalah adanya beberapa guru yang masih awam menggunakan computer sehingga tim pengabdi harus mengajarkan dulu dasar-dasar komputer. Suasana pelatihan pada guru-guru SDN 02 Palembang dapat dilihat pada gambar 2.

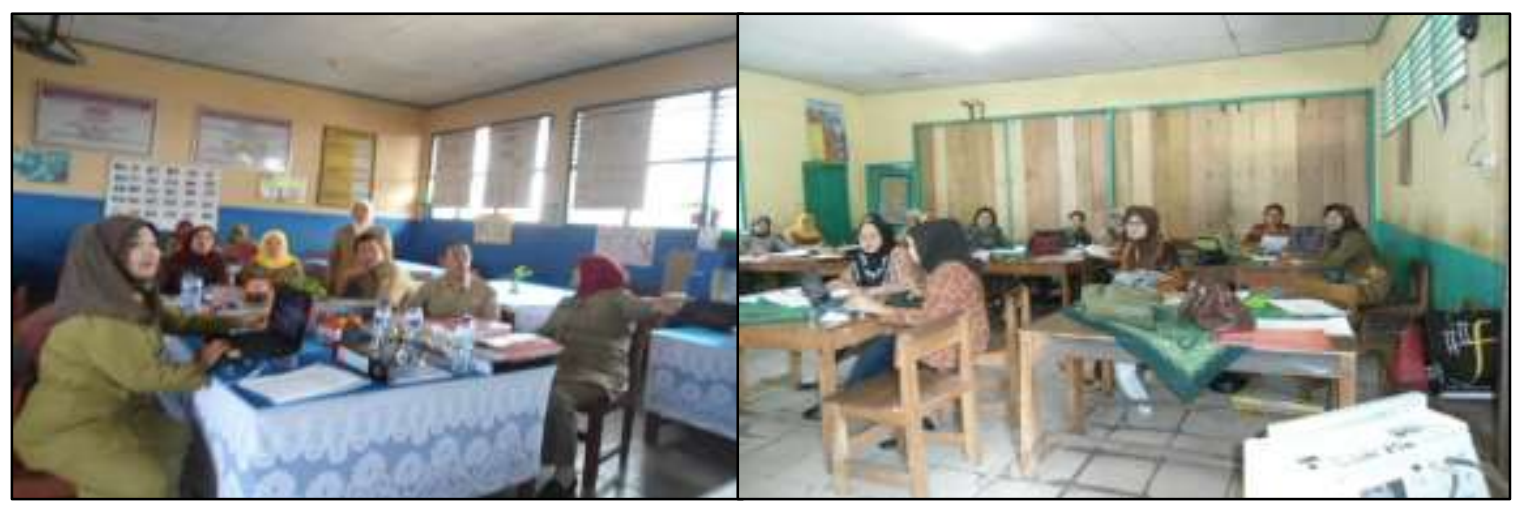

Gambar 2. Foto-foto kegiatan pengabdian

Penjelasan materi dimulai melalui modul mulai dari menjalaskan fungsi-fungsi menu yang sering dipakai dalam pembuatan slide, membuat animasi, konversi video, dan membuat kuis interaktif. Semua materi dapat disampaikan beriringan dengan praktek pembuatan slide. Diharapkan materi yang telah disampaikan dan dipraktekkan oleh guru-guru ini dapat dipahami dan diterapkan pada saat proses pembelajaran di kelas. beberapa materi yang masih belum dapat dipahami pada saat pelatihan dapat diulang dan dipraktekkan kembali oleh para guru dilain waktu dengan acuan modul yang diberikan oleh tim pengabdi.

Pembuatan bentuk interaktif tidak hanya kuis namun lebih banyak ke pola interaktif dalam bentuk menu. Dalam pembuatan menu cukup memakan waktu untuk pelatihannya karena setiap peserta harus menggambar melalui PowerPoint, mengambil gambar dari internet untuk dimasukkan ke PowerPoint, menambahkan animasi pada tulisan, dan mengkonversi ke video, serta membuat kuis interaktif di PowerPoint.

Dari pelatihan tersebut para guru berhasil mempraktekkan materi PowerPoint dari memilih tampilan slide, desain slide, animasi slide, konversi materi ppt menjadi video, dan membuat kuis. Gambar 3 merupakan salah satu contoh hasil pembuatan PowerPoint untuk mata pelajaran matematika. Pada Gambar 3 tersebut terlihat bahwa peserta telah dapat membuat 
slide dengan tampilan yang baik, menambah efek transisi, dan menambahkan gambar sebagai ilustrasi pembelajaran.

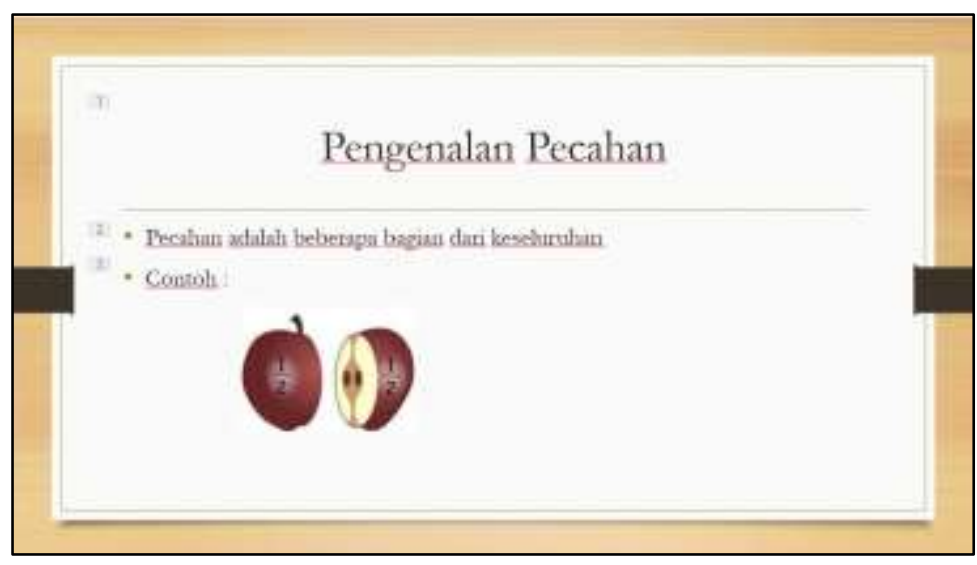

Gambar 3. Contoh salah satu hasil slide PowerPoint peserta

Untuk mengevaluasi bagaimana penguasaan peserta terhadap materi yang diberikan, tim pengabdi membuat penilaian dari slide PowerPointyang disajikan oleh peserta dengan beberapa kriteria seperti yang terlihat pada Tabel 2 . Penilaian menggunakan 4 skor yaitu: Kurang $(K)=$ 1, Cukup Baik $(C B)=2$, Baik $(B)=3$, dan Sangat Baik $(S B)=4$

Tabel 2. Kriteria penilaian pelatihan

\begin{tabular}{llll}
\hline \multicolumn{1}{c}{ Kriteria } & \multicolumn{3}{c}{ Skor } \\
\cline { 2 - 4 } & $\mathbf{1}$ & $\mathbf{3}$ & $\mathbf{4}$ \\
\hline Pengenalan Menu (PM) & & & \\
Membuka, membuat file baru, menyimpan & & & \\
file, membuat tabel, menyisipkan shape, & & & \\
gambar, dan SmartArt, menu transition, & & \\
menu animation, Slide show & & \\
\hline Teks dan Gambar (TDG) & & \\
Pemilihan font, teks dan tulisan dapat \\
dibaca, tata letak teks dan gambar, \\
penggunaan kalimat yang singkat dan jelas \\
\hline Background (BG) \\
Desain slide, keselarasan warna huruf dan \\
background \\
\hline Membuat Animasi (MA) \\
Tampilan animasi, penambahan musik, efek \\
transisi, penggunaan dan penempatan \\
animasi yang tepat \\
\hline Konversi Video (KV) \\
Kualitas tampilan gambar dan suara, \\
kesesuaian musik pengiring dengan materi \\
yang disajikan \\
\hline Membuat Kuis (MK) \\
Membuat soal essay, membuat soal pilihan \\
ganda
\end{tabular}

Hasil penilaian terhadap kemampuan rata-rata peserta dalam membuat media pembelajaran berbasis PowerPoint dapat dilihat pada tabel 3. Skala penilaian terhadap 
penguasaan materi yang diberikan menggunakan skala 1 sampai skala 4 . Untuk rata-rata 1 1,9 berarti penguasaan peserta adalah kurang, rata-rata 2,1-2,9 berarti penguasaan peserta adalah cukup baik, dan rata-rata $3-3,9$ berarti penguasaan peserta adalah baik.

Tabel 3. Penilaian hasil karya pelatihan

\begin{tabular}{|c|c|c|c|c|c|c|c|}
\hline \multirow[b]{2}{*}{ No } & \multirow{2}{*}{ Nama Guru } & \multicolumn{6}{|c|}{ Materi } \\
\hline & & PM & TDG & BG & MA & KV & MK \\
\hline 1 & Emiliya, S.Pd, Mm & 3 & 3 & 3 & 3 & 3 & 2 \\
\hline 2 & Syamsidar, S.Pd. & 3 & 3 & 3 & 3 & 3 & 3 \\
\hline 3 & Hj. Subranti, S.Pd & 3 & 3 & 3 & 2 & 3 & 2 \\
\hline 4 & Hj. Msy. Putri Nuraini, S.Pd.Sd & 3 & 3 & 3 & 2 & 3 & 2 \\
\hline 5 & Hj. Maimunah, S.Pd.Sd & 3 & 3 & 2 & 3 & 3 & 2 \\
\hline 6 & Husniati, S.Pd & 3 & 3 & 3 & 3 & 3 & 3 \\
\hline 7 & Mardiana, S.Pd.Sd & 3 & 3 & 3 & 3 & 3 & 3 \\
\hline 8 & Hj. Wellina, S.Pd. & 3 & 3 & 3 & 2 & 3 & 3 \\
\hline 9 & Rosmawati, S.Pd.Sd & 3 & 3 & 3 & 3 & 3 & 3 \\
\hline 10 & Nurlaila, S.Pd.Sd & 3 & 3 & 3 & 3 & 3 & 3 \\
\hline 11 & Hj. Suhartini, S.Pd.Sd & 3 & 3 & 3 & 3 & 3 & 3 \\
\hline 12 & Sri Husnani, S.Pd & 3 & 3 & 3 & 3 & 3 & 3 \\
\hline 13 & Siti Nurpada, S.Pd & 3 & 3 & 3 & 3 & 3 & 3 \\
\hline 14 & Jasmer Gultom, S.Pd & 3 & 3 & 3 & 3 & 3 & 3 \\
\hline 15 & Hj. Husniah Zulfa, A.Ma.Pd & 3 & 3 & 2 & 3 & 3 & 3 \\
\hline 16 & Ruwaida, A.Ma.Pd & 3 & 3 & 3 & 3 & 3 & 3 \\
\hline 17 & Syamsiar Rusnaini, A.Ma & 3 & 3 & 3 & 3 & 3 & 2 \\
\hline 18 & Sriwijaya Yanto, S.Pd & 3 & 3 & 3 & 3 & 3 & 3 \\
\hline 19 & Suprihatin, S.Pd.Sd & 3 & 3 & 3 & 3 & 3 & 3 \\
\hline 20 & Ribkoh, S.Pd & 3 & 3 & 2 & 3 & 3 & 3 \\
\hline 21 & Yuliana, S.Pd.I & 3 & 3 & 3 & 3 & 3 & 3 \\
\hline 22 & Nirma Yunita, S.Pd & 3 & 3 & 3 & 2 & 3 & 3 \\
\hline 23 & Gian Handini, S.Pd & 3 & 3 & 3 & 3 & 3 & 3 \\
\hline 24 & Banu Krisna Mahardika, S.Pd & 3 & 3 & 3 & 3 & 3 & 3 \\
\hline & Skor total & 72 & 72 & 69 & 68 & 72 & 67 \\
\hline & Rata-rata & 3 & 3 & 2,87 & 2,83 & 3 & 2,79 \\
\hline
\end{tabular}

Materi yang diberikan pada guru-guru SDN 02 Palembang adalah mulai dari pengenalan menu-menu PowerPoint, memilih font untuk tulisan, menambah gambar, memilih background yang baik, dan menambah animasi pada slide. Agar pembelajaran menjadi lebih menarik ditambahkan materi konversi video dan membuat kuis dengan menggunakan PowerPoint. Secara keseluruhan guru-guru SDN 02 palembang telah memahami materi yang diberikan dengan baik.

Dari Tabel 3 diatas dapat dilihat nilai rata-rata penguasaan materi pada tiap-tiap kriteria. Untuk kriteria pengenalan menu (PM), teks dan gambar (TDG), dan konversi video (KV) penguasaan para peserta sudah baik. Guru-guru SDN 02 Palembang telah memahami menumenu yang sering digunakan untuk membuat slide pada Microsoft PowerPoint, mulai dari membuka PowerPoint, membuat file baru, menyimpan file, membuat tabel, menyisipkan shape, gambar, dan SmartArt, membuat transition, membuat animation, dan slide show. Hasil slide yang dibuatpun sudah baik. Pemilihan font yang tepat sehingga teks dan tulisan dapat dibaca, tata letak teks dan gambar yang nyaman dilihat, dan penggunaan kalimat yang singkat dan 
jelas. Demikian juga dengan hasil video slide, menampilkan gambar yang berkualitas dan jelasnya suara musik pengiring yang didengar ketika musik pengiring dihidupkan, serta kesesuaian musik pengiring dengan materi yang disajikan.

Untuk kriteria background (BG), membuat animasi (MA), dan membuat kuis (MK) penguasaan para peserta adalah cukup baik. Ada beberapa slide peserta yang tidak terbaca dengan jelas dikarenakan warna huruf dan background tidak selaras, juga dengan tampilan dan penempatan animasi, pemberian efek transisi yang kurang tepat, serta masih kurangnya penguasaan materi peserta dalam membuat soal esai dan membuat soal pilihan ganda.

Beberapa pelatihan mengenai power point bagi guru-guru sekolah dasar telah dilakukan oleh beberapa pengabdi sebelumnya. (Salamah, Lindawati, Asriyadi, \& Kusumanto, 2019) memberikan pelatihan power point bagi guru-guru SDN 130 Palembang. Materi yang diberikan adalah pengenalan PowerPoint dan membuat animasi. Metode yang digunakan adalah presentasi, demonstrasi, dan praktik. Hasil yang dicapai setelah pelatihan adalah Peserta dapat membuat tulisan, membuat rancangan tampilan, mengatur animasi tampilan pada program power point untuk kebutuhan presentasi. Selain itu pelatihan yang sejenis juga dilakukan oleh (Minardi \& Akbar, 2020) yang memberikan pelatihan PowerPoint bagi guru-guru SD di Semarang. Metode yang digunakan adalah identifikasi, pelatihan, dan pendampingan. Hasil yang dicapai setelah pelatihan adalah adanya guru-guru SD di Semarang dapat membuat materi pembelajaran yang lebih menarik dengan menggunakan media pembelajaran PowerPoint.

Dari hasil pengabdian sebelumnya terlihat pentingnya PowerPoint untuk peningkatan proses pembelajaran maka pelatihan PowerPoint bagi para guru sangat diperlukan. Dengan adanya pelatihan PowerPoint ini tentunya akan meningkatkan kompetensi dan kemampuan guru-guru dalam mengajar yang tentunya hal ini akan meningkatkan profesionalisme para guru yang akan berdampak pada meningkatnya kualitas proses belajar mengajar di kelas.

\section{Kesimpulan}

Berdasarkan hasil dari pelatihan yang diberikan rata-rata penguasaan guru-guru SDN 02 Palembang terhadap materi yang diberikan adalah baik. Penilaian untuk materi pengenalan menu, teks dan gambar, dan konversi video adalah baik. Sedangkan penilaian untuk background, membuat animasi, dan membuat kuis adalah cukup baik. Beberapa guru yang sebelum pelatihan tidak mengerti dan memahami PowerPoint, dapat mengerti dan memahami mengenai PowerPoint setelah pelatihan. Bagi guru-guru yang sebelumnya telah menggunakan PowerPoint dalam pengajarannya dapat lebih memahami dan dapat membuat materi ajar dengan lebih baik lagi, lebih atraktif, dan lebih menarik dengan menggunakan PowerPoint. Adanya pelatihan ini diharapkan dapat lebih meningkatkan profesionalisme guru-guru SDN 02 Palembang dalam proses belajar mengajar dikelas, karena profesionalisme seorang guru salah satunya dinilai dari kompetensi mengajar dengan menggunakan media pembelajaran.

Dengan adanya pelatihan ini guru-guru SDN 02 Palembang dapat mengoptimalkan performa software komputer yang telah dikenal untuk meningkatkan mutu pembelajaran dan profesionalismenya dengan mengeksplorasi fitur-fitur yang belum banyak digunakan. 
Komunikasi antara tim pengabdi dan para guru juga terjalin dengan baik. Pelatihan PowerPoint bagi guru-guru SDN 02 Palembang telah berhasil dilaksanakan oleh tim pengabdi dari Jurusan Teknik Elektro Polsri. Guru- guru di SDN 02 Palembang memberikan tanggapan yang positif terhadap pelatihan PowerPoint ini. Hal ini dapat dilihat dari respon dan pertanyaan para peserta pada saat pelatihan. Pada akhir pelatihan para peserta memberikan masukan agar dapat diadakan kegiatan lanjutan program pelatihan seperti ini dengan software animasi lain seperti Prezidan Libre Office agar kemampuan membuat animasi bagi guru-guru sekolah dasar semakin berkembang khususnya bagi guru-guru SDN 02 Palembang.

\section{Ucapan Terima Kasih}

Ucapan terimakasih penulis sampaikan kepada Politeknik Negeri Sriwijaya, khususnya kepada P3M Politeknik Negeri Sriwijaya yang telah mendukung dengan memberikan bantuan dana untuk pengabdian ini. Selain itu juga penulis mengucapkan terimakasih kepada Kepala Sekolah dan guru-guru SDN 02 Palembang yang telah memberikan fasilitas dan support dalam melaksanakan kegiatan pelatihan ini di SDN 02 Palembang. Semoga pengabdian ini bermanfaat untuk meningkatkan proses belajar mengajar di kelas.

\section{Referensi}

Afrida, A., Harizon, H., Bakar, A., \& Sanova, A. (2018). Pelatihan Pengembangan Media Pembelajaran Interaktif Berbasis Multimedia Sebagai Upaya Meningkatkan Kompetensi Profesionalisme dan Kreativitas Guru-Guru SMA Muaro Jambi. Jurnal Karya Abdi Masyarakat, 2(1), 15-22. DOI: https://doi.org/10.22437/jkam.v2i1.5426

Analisadaily. (2017). Guru Profesional Harus Melek Teknologi. Retrieved from https://analisadaily.com/berita/arsip/2017/11/25/458117/guru-profesional-harus-melekteknologi/

Gilbert, D. (2002). Multimedia Technology. Queensland.

Hartono, H., Lesmana, C., Permana, R., \& Matsun, M. (2018). Pelatihan dan pendampingan pembuatan media pembelajaran berbasis multimedia interaktif. Transformasi: Jurnal Pengabdian Masyarakat, 14(2), 139-147. https://doi.org/10.20414/transformasi.v14i2.587

Ivers, K. S., \& Barron, A. E. (2002). Multimedia Projects in Education: Designing, Producing, and Assessing. Diakses di http://books.google.com/books?id=Adi07NylHwcC\&pgis=1

Mayer, R. E., \& Moreno, R. (1998). Aids to computer-based multimedia learning. California, USA.

Minardi, J., \& Akbar, A. S. (2020). Pelatihan Pengembangan Media Pembelajaran Interaktif dengan Power Point untuk Peningkatan Kompetensi Guru SD. E-Dimas: Jurnal Pengabdian Kepada Masyarakat, 11(1), 96. DOI: https://doi.org/10.26877/e-dimas.v11i1.2747

Nina. (2016). Sebelum dan Sesudah Ada Teknologi Pendidikan. Kompasiana.Com. Diakses di https://www.kompasiana.com/amanina/57071d63ee927339055ab53c/sebelum-dan-sesudahada-teknologi-pendidikan?page $=2$

Nugraheni, C. E. (2013). Pembelajaran Dulu dan Sekarang. Diakses di http://pip.unpar.ac.id/publikasi/buletin/sancaya-vol-02-no-03-edisi-mei-juni2014/pembelajaran-dulu-dan-sekarang/

Riskiawan, H.Y., Setyohadi, D.P.S., \& Arifianto, A.S. (2016). Pelatihan pengembangan media pembelajaran berbasis multimedia untuk meningkatkan kualitas dan kreativitas guru SMA. Jurnal Pengabdian Masyarakat J-DINAMIKA, 1(1), 48-52.

Rusman. (2011). Model-Model Pembelajaran Mengembangkan Profesionalisme Guru. Jakarta: PT Raja Gafindo Persada.

Salamah, I., Lindawati, Asriyadi, \& Kusumanto, R. (2019). Peningkatan Kemampuan Guru-Guru SD 
Negeri 130 Palembang Dalam Menyajikan Presentasi Atraktif Melalui Pelatihan Microsoft Power Point. Aksiologiya: Jurnal Pengabdian Kepada Masyarakat, 4(1), 52. DOI: https://doi.org/10.30651/aks.v4i1.2197

Supriyono, H., Sujalwo, Sapoetra, A., \& Rahayu, E. T. (2015). Pelatihan pengembangan media pembelajaran berbasis web bagi guru SMP dan SMA Muhammadiyah Kartasura. Jurnal Warta, $18($ No.2), 98-109.

Yossie. (2011). Pembelajaran berbasis multimedia. Diakses di https://yossiekudotcom.wordpress.com/2011/09/27/pembelajaran-berbasis-multimedia/ 


\section{Lampiran}

Tabel 1. Angket pra-pelatihan PowerPoint

\begin{tabular}{|c|c|c|}
\hline No & Pertanyaan (Q) & Jawaban (Ya/Tidak) \\
\hline Q1 & Apakah anda tahu mengenai PowerPoint? & \\
\hline Q2 & $\begin{array}{l}\text { Apakah anda tertarik menggunakan PowerPoint sebagi media } \\
\text { pembelajaran di kelas? }\end{array}$ & \\
\hline Q3 & $\begin{array}{l}\text { Apakah anda pernah menggunakan PowerPoint dalam } \\
\text { pembelajaran di kelas? }\end{array}$ & \\
\hline Q4 & $\begin{array}{l}\text { Menurut anda apakah PowerPoint berguna untuk meningkatkan } \\
\text { kualitas pembelajaran di kelas? }\end{array}$ & \\
\hline Q5 & Apakah anda mengetahui fitur-fitur yang ada pada PowerPoint? & \\
\hline Q6 & $\begin{array}{l}\text { Apakah anda mengerti dan memahami fitur-fitur yang ada pada } \\
\text { PowerPoint? }\end{array}$ & \\
\hline Q7 & $\begin{array}{l}\text { Tahukah anda cara membuat materi dengan menggunakan } \\
\text { PowerPoint? }\end{array}$ & \\
\hline Q8 & $\begin{array}{l}\text { Tahukah anda cara membuat animasi dengan menggunakan } \\
\text { PowerPoint? }\end{array}$ & \\
\hline Q9 & $\begin{array}{l}\text { Tahukah anda cara membuat kuis dengan menggunakan } \\
\text { PowerPoint? }\end{array}$ & \\
\hline Q10 & $\begin{array}{l}\text { Tahukah anda cara konversi ke video dengan menggunakan } \\
\text { PowerPoint? }\end{array}$ & \\
\hline
\end{tabular}

